\title{
Investigating the Drivers of Pro-Environmental Behaviour: A Household Waste Minimisation Case
}

\author{
Manoj Govind Kharat (Corresponding author) \\ National Institute Of Industrial Engineering (NITIE) \\ Vihar Lake, Powai, Mumbai, 400087, Maharashtra, India \\ E-mail: manojgkharat@gmail.com \\ Shankar Murthy \\ National Institute Of Industrial Engineering (NITIE) \\ Vihar Lake, Powai, Mumbai, 400087, Maharashtra, India \\ E-mail: murthyshanker@gmail.com
}

Sheetal Jaisingh Kamble

National Institute Of Industrial Engineering (NITIE)

Vihar Lake, Powai, Mumbai, 400087, Maharashtra, India

E-mail: sheetaljkamble@ gmail.com

Mukesh Govind Kharat

National Institute Of Industrial Engineering (NITIE)

Vihar Lake, Powai, Mumbai, 400087, Maharashtra, India E-mail:mukeshgkharat@gmail.com

Received: April 12, 2017 Accepted: May 28, 2017 Published: June 2, 2017

doi:10.5296/iss.v5i1.11058 URL: https://doi.org/10.5296/iss.v5i1.11058 


\title{
Macrothink
}

\begin{abstract}
Identifying and analysing the drivers of household pro-environmental behaviour (PEB) is a question of great interest. Providing an answer to this question investigating PEB has implications for planners and policymakers. The currents study attempts to identify and analyse the drivers that contribute to PEB significantly. To achieve this, an in-depth literature review and qualitative analysis were carried out. A questionnaire was developed to measure the PEB construct and its determinants. Next, the reliability of the questionnaire was assessed followed by Pearson's correlational analysis. Results indicate that PEB comprises of nine dimensions viz., behavioural intention, attitude, personal moral norms, subjective norms, situational factors, perceived behavioural control, community concern, internal attribution and perceived consequences. The study results provide significant insights to help more people act in pro-environmental ways. From the theoretical perspective, the study results provide empirical evidence to researchers and a reliable and valid scale to measure PEBs.
\end{abstract}

Keywords: pro-environmental behaviour, social concern, determinants of PEB, household waste minimisation; reliability analysis, Pearson's correlation 


\section{Introduction}

With every passing year, the environmental problems are becoming severe. The increasing amount of Municipal Solid Waste (MSW) with increasing populations in developing countries has become a potential threat to the environment, to society and leads to economic losses (Shekdar, 2009). Today many cities are considered unsustainable mainly due to the pressures of industrial development, technological improvements, and concentration of populations. On that ground, the concept of sustainability has emerged as a new way of thinking. Given increasing amounts of waste being generated as a consequence of rapidly developing economies, sustainable household waste management has become an important concern for local and national authorities worldwide (Barr et al., 2001a, 2004; Davies, 2003; Barr, 2007).

Most of the environmental problems are, at least partly, rooted in human behaviour. More recently, there has been considerable public attention on reducing the volume of waste going into landfills through the promotion of various environmental behaviours, such as waste reduction, recycling, reusing and composting. Waste minimisation is a behaviour which requires considerable efforts on the part of the individual, as household waste must be sorted, prepared and stored. Consequently, the decision is likely to be complex and several factors to be taken into consideration. Practically, it is more efficient and economical to decrease the amount of waste that enters the waste stream rather than dealing with materials after they are discarded. Waste minimisation offers people an additional means, of helping the environment.

Waste minimisation is an important category of behaviours to consider. Although waste minimisation is not a new concept, there is evidence to suggest that this behaviour is unfamiliar to people and that it is not performed to the same extent or with the same frequency. Yet, despite the fact that people have positive attitudes toward these conservation behaviours (Berger and Corbin, 1992), participation in different waste management programs varies widely (McCarty and Shrum, 1994). Waste minimisation behaviour has received increasing attention from researchers over the past few years. The majority of the studies in the existing literature have attempted to describe factors, which are related to the performance of waste minimisation behaviours. Some of the factors which have been shown to facilitate waste minimisation behaviour are attitudes and motives, social norms, lifestyle choices and beliefs etc. Although earlier studies have documented relationships between various psychological variables and self-reported waste reduction, the work has primarily been descriptive in nature and not theory driven. The question of how to examine individual attitudes and behaviour and, more significantly, how to introduce meaningful policies, is particularly problematic in the realm of waste management. A balance must be struck between qualitative insights and quantitative generalisation. There is also the problem of representativeness since all householders are stakeholders in the search for environmental sustainability. Because of the economic and environmental advantages of waste minimisation behaviour, it is important to develop scientific approaches to ensure adequate understanding. The literature on waste minimisation behaviour is small and lacks useful theoretical models. This study attempts to examine the usefulness of a theoretical 
model to explain and predict waste minimisation behaviour and perhaps other PEBs as well. In order to promote PEB i.e. waste minimisation effectively, an essential first step is to enhance the understanding of the factors influencing individual's engagement in PEB, this will help to develop effective policies and frame initiatives that promote PEBs. Thus, it is noteworthy and interesting to study, which factors influence individual PEB? Although a wide variety of factors have been identified as influencing environmental behaviour, little is known about the relative influence of each of these factors on individual waste management behaviour.

A variety of cognitive and psycho-social variables that may influence environmental behaviour have been identified. Overall, the variables identified previously have been found to be significantly related to environmental behaviour. However, in many cases, weak or equivocal relationships have been reported. In addition, the relative importance of these variables is not well understood. This may be because these variables are often studied separately, in a piecemeal fashion, with only one or a few variables studied at a time. Although multivariate models of environmental behaviour, which include both moderating and mediating variables, have been proposed (Balderjahn, 1988; Hines et al., 1987; Pieters, 1991; Jackson et al., 1993; McCarty and Shrum, 1993, 1994), none have successfully integrated all of the previously outlined variables into a single framework; and, in general, the earlier research lacks a strong theoretical foundation.

\subsection{The Theory of Planned Behaviour (TPB)}

The TPB (Ajzen, 1985, 1991) provides a basis for an integrated waste management model and is an extension of the well-known Theory of Reasoned Action (Azjen and Fishbein, 1980; Fishbein and Ajzen, 1975). In the TPB model, behaviour (B) is a direct function of behavioural intention (BI), which in turn, is formed by attitude (A), which reflects feelings of favour or disfavour toward a behaviour; subjective norm (SN), which reflects perceptions that significant referents desire the person to perform or not to perform a behaviour; and perceived behavioural control (PBC), which reflects beliefs regarding control over factors that may facilitate or impede the performance of a behaviour (Ajzen, 1985, 1991; Ajzen and Madden, 1986).

Stated formally, $\mathrm{BI}=\mathrm{w}_{1} \mathrm{~A}+\mathrm{w}_{2} \mathrm{SN}+\mathrm{w}_{3} \mathrm{PBC}$. It is $\mathrm{PBC}$ that distinguishes the TPB from the Theory of Reasoned Action. Perceived behavioural control is determined by two factors: (1) facilitating conditions (Triandis, 1979), which reflect the availability of resources, such as time, money, and effort, needed to engage in a behaviour and (2) self-efficacy, that is, a person's perception of or self-confidence in his or her ability to perform a behaviour (Bandura, 1977, 1982). Perceived behavioural control has an influence on intention on the basis of a person's assessment of the likelihood of success in performing the behaviour (Ajzen and Madden, 1986).

BI directly influences behaviour. Ajzen (1985, 1991) and Ajzen and Madden (1986) assert that PBC will also directly influence behaviour. This occurs to the extent that PBC reflects the actual ability to perform the behaviour. Thus, it can be stated that $\mathrm{B}=\mathrm{w} 4 \mathrm{BI}+\mathrm{w} 5 \mathrm{PBC}$. Each of the determinants of intention (i.e., A, SN, and PBC) is, in turn, determined by 
underlying belief structures, namely, attitudinal beliefs $\left(b_{i}\right)$, normative beliefs $\left(n b_{j}\right)$, and control beliefs $\left(\mathrm{cb}_{\mathrm{k}}\right)$. Stated formally, A equals the $\mathrm{b}_{\mathrm{i}}$ that performing a behaviour will lead to a particular outcome multiplied by an evaluation of the desirability of that outcome $\left(\mathrm{e}_{\mathrm{i}}\right)$; that is, $A=\sum b_{i} e_{i}$.

Subjective norm is the person's $\mathrm{nb}_{\mathrm{j}}$ concerning the influence of a particular referent (e.g., family or friends) multiplied by the motivation to comply with that referent $\left(\mathrm{mc}_{\mathrm{j}}\right)$; that is,

$\mathrm{SN}=\sum \mathrm{nb}_{\mathrm{j}} \mathrm{mc}_{\mathrm{j}}$.

Perceived behavioural control is the sum of the control beliefs $\left(\mathrm{cb}_{\mathrm{k}}\right)$ multiplied by the perceived facilitation $\left(\mathrm{pf}_{\mathrm{k}}\right)$ of the control factor in either inhibiting or facilitating the behaviour; that is, $\mathrm{PBC}=\sum \mathrm{cb}_{\mathrm{k}} \mathrm{Pf}_{\mathrm{k}}$.

\subsection{Norm Activation Model (NAM)}

Schwartz (1977) originally developed the NAM in the context of altruistic behaviour. Personal norms form the core of this model. Schwartz (1977) states that these norms are actively experienced "as feelings of moral obligation not as intentions". These personal norms are used in the NAM to predict individual behaviour. The model states that these personal norms are determined by two factors: the awareness that performing (or not performing) a particular behaviour has certain consequences, and the feeling of responsibility for performing the specific behaviour (Schwartz, 1977). This model is used in our study to explore how anticipated pride and guilt are associated with personal norms and behaviour within the original NAM.

\subsection{Integration of NAM and TPB in Literature}

Some studies (Bamberg et al., 2007; Bamberg and Möser, 2007) have integrated the NAM with the Theory of Planned Behaviour (Ajzen, 1991). Previous studies that have integrated the NAM and the TPB have found that the influence of personal norms on behaviour is mediated by intentions. Moreover, these studies have found that including intentions in the NAM increases the explained variance in behaviour (Bamberg and Möser, 2007; Bamberg et al, 2007). This finding underlines Ajzen's (1991) views that intention is the most immediate and important predictor of behaviour, and that intention mediates the influence of other variables, even affective ones. Additionally, studies that include personal norms within the TPB show that personal norms increase the explained variance of behavioural intentions and behaviour in the TPB (Harland et al., 1999). Taken together, these findings imply that an integrated NAM-TPB model can best explain pro-environmental behaviour. Therefore, the current study not only explores how anticipated pride and guilt relate to personal norms and behaviour within the NAM but also within an integrated NAM-TPB model.

Factors that have been studied include the perceived benefits of the behaviour, difficulty of the behaviour, perceived barriers to performing the behaviour, perceived effectiveness of the behaviour, knowledge of the behaviour, and social influences on the behaviour. The integrated waste management model is an extension of the TPB and NAM. However, in the model, the structures, which are treated as monolithic in the TPB model, NAM model, and 
additional factors were decomposed on the basis of known determinants in the broader social psychology literature. These factors are related to those variables found to be influential in prior environmental research.

In summary, the integrated waste management model suggests that waste reduction behaviour is a function of behavioural intention and perceived behavioural control. The intention is, in turn, determined by attitude, subjective norm, personal norms, situational factors and perceived behavioural control. These determinants of intention are modelled as a function of certain beliefs. Attitude is a function of both perceived (personal and societal) relative advantages, environmental emotions, environmental cognition and complexity; the subjective norm is a function of both internal and external normative influences, perceived behavioural control is a function of self-efficacy, complexity, and facilitating conditions. Personal norms as a function of awareness of consequences, the ascription of responsibility and internal attribution.

\section{Conceptual Model}

The study seeks to understand better how these factors combine to influence people to act in a pro-environmental manner. The specific behaviour of interest is source minimisation and the diversion of materials from the waste stream. To understand these behaviours, the current study employed an integrative model of PEB (waste management behaviour). The integrated model is based on the TPB (Ajzen 1985, 1991) from the attitude-behaviour literature and NAM (Schwartz, 1977) incorporating a variety of factors thought to be key determinants of waste management behaviour. It seemed inappropriate to use the original TPB and NAM because (a) focus was not to test a certain model, the (b) need is to identify intervention related model factors. This model enables us to examine simultaneously the relative influence of a wide variety of variables that have been identified as important determinants of waste management behaviour variables that have, to date, been typically studied in a piecemeal fashion. The model integrates all of the variables from both the theories along with additional factors such as existing infrastructures, situational factors as a possible means of increasing the salience of the model concepts among study participants and places them into a theoretical framework for the prediction of waste reduction behaviour. The model enables us to examine the relative influence of different variables and suggests factors that may mediate the relationships between these variables and environmental behaviour. In this way, the model provides a comprehensive framework that enables decision makers to predict the influence of these variables on environmental behaviour. The need for such a comprehensive framework has been previously identified in the literature. The theoretical focus of the study is to develop a model of how behaviour suitable for developing interventions is determined in general. The research is designed to accomplish the following two goals: first, to develop items that can be used to assess justifications for engaging in PEB (waste minimisation behaviour and second, to investigate the relationship between these variables.

The brief definition of the PEB model constructs (in the context of waste minimisation) included in the study is explained below:

Waste minimisation behaviour - frequency of minimisation, past behaviour. 
Subjective norm - the individual's perception of social pressure to minimise household waste.

Perceived behavioural control - the individual's perception of their ability to perform the behaviour.

Situational factors- physical factors (infrastructure) which may facilitate or inhibit waste minimisation behaviour.

Perceived consequences of waste minimisation- the outcomes of performing the targeted behaviour.

Attitudes to waste minimisation - the respondents were asked the extent to which they engaged in a number of waste minimisation behaviours.

Community concern - Concern for the community and society in the daily behaviour.

Internal attribution - the feeling of guilt, the shame of not behaving in the environmentally friendly way.

Personal moral norms - the moral norms of the person e.g. felt responsibility etc.

Behavioural intention - the intention of the individual to engage or not to engage in PEB, future minimisation intentions.

\section{Methodology}

In order to achieve the stated objectives, the following methodological steps were followed:

1. Item generation for the questionnaire with the help of extensive literature review and focus group interviews;

2. Data collection for pilot study;

3. Testing the scale for reliability and validity;

4. Analysing the item-to-total correlation and coefficient to assess the reliability of the scale and improve upon items to improve the reliability of the scale;

5. Pearson's correlation analysis

\subsection{Item Generation}

Development of the scales to measure each of the constructs in the model proceeded through a series of steps. Items to measure behavioural intention, attitude, subjective norm, and perceived behavioural control were generated on the basis of the procedures suggested by Ajzen and Fishbein (1980) and Ajzen (1985, 1991) and through literature. The items for personal norms, situational factors were gathered from the literature. The pool of items for different constructs of the model was generated from the literature review, expert opinion and focus group interviews. Purposive sampling was used to select participants for the focus groups. Salient beliefs about waste reduction were elicited from a convenience sample of 20 people. The beliefs were mapped into measures of perceived consequences, community concern, facilitating conditions, environmental emotions, cognition and internal attribution. 


\section{Macrothink}

To do this, a larger sample of raters was asked to sort the beliefs into categories representing each of the underlying constructs. This sorting procedure was used to refine the belief items prior to conducting the pilot study. After this item for each construct was finalised from both the literature and ratings by respondents and the questionnaire was finalised for the pilot study. The questionnaire was then modified and one hundred participants (a different sample than that used for the elicitation and sorting tasks) completed the pilot test. On the basis of the results of the pilot test, the questionnaire was further modified for use in the main study.

\subsection{Content Validity}

In total, 52 items under ten factors were reviewed by ten experts comprising of academicians, psychologists, consultants and public authorities to assess the content and face validity. The experts evaluated the items for clarity, representativeness and possibility of misinterpretation. The experts suggested rewording/reframing of few items.

\subsection{Scale and Measurement}

The current study used a measure of ten latent variables. The self-administered questionnaire was used to collect the data; the scale was tested for reliability and validity; the item-to-total correlation and coefficient were used to assess the reliability of the scale and improve upon items to improve the reliability of the scale. The responses were recorded on 5 points Likert scale measuring, (Strongly Disagree $=1$, Disagree $=2$, Neutral $=3$, Agree $=4 \&$ Strongly Agree $=5$ ) recording their level of agreement with each statement of the ten dimensions of PEB.

\subsection{Questionnaire Administration}

Questionnaires were administered personally to the household respondents. Doubts and Queries raised by the respondents with regard to any question were clarified instantly on the spot. Only one person per household was asked to complete the survey. The survey measured all constructs in the model. Additional items were placed on the questionnaire to assess the background characteristics of the respondents such as socio-demographic data stating sex, age, education, occupation, income, and household size were also recorded. The questionnaire was tested for reliability.

\subsection{Data Collection}

Simple random sampling technique was used for the data collection. A sample of 250 respondents completed the survey.

\section{Data Analysis and Results}

The data that were collected was analysed through the use of a statistical package - Statistical Package for Social Sciences (SPSS Version 20). The data were analysed using reliability, validity and exploratory factor analysis (EFA) to assess the psychometric properties of the scale. 


\subsection{Reliability and Item Analysis}

As recommended by Churchill (1979), the first and the foremost step to refine the scale is the computation of coefficient a, i.e. Cronbach alpha (Cronbach, 1951). Reliability was assessed through the following means -

(a) item-to-item correlation is more than 0.3 ,

(b) item-to-total (summated scale) correlation is more than 0.5 , and

(c) Cronbach's alpha is at least 0.7 .

For all factors of PEB, Cronbach alpha was computed, that ranged from 0.70 to 0.94 (pilot study, $\mathrm{n}=100)$. According to Nunnally's criterion, the minimum satisfactory value of Cronbach alpha is 0.7 (Nunnally, 1974). Although the criterion of alpha was satisfied, further to improve the value of alpha, corrected item-to-total correlation for each cluster of items were computed. Items possessing very low correlations and/or items whose correlations produce sharp drop among the corrected item-to-total correlations and/or items whose removal improves the value of alpha were deleted. This iterative sequence was repeated numerous times which resulted in the form of 49 items and three items being deleted. The improved values of Cronbach's alpha for all 10 factors ranged from 0.81 to 0.97 specifying good internal consistencies among all the items. Further, the combined reliability was computed for all the 49-items (Nunnally, 1978) and it was found to be quite high, i.e. 0.91. Finally, total 49 items for all the 10 factors were retained for the next stage.

After item analysis, the questionnaire was used to collect data from a new sample $(n=250)$. Again the reliability was computed and the improved values of Cronbach's alpha for all 10 factors ranged from 0.89 to 0.96 . These values are shown in Table 1.

Table 1. Reliability of constructs

\begin{tabular}{lcc}
\hline \multicolumn{1}{c}{ Construct } & Reliability & Item to total Correlation (above 0.5) \\
\hline Behaviour & 0.890 & All \\
Behavioural Intention & 0.891 & All \\
Perceived Behaviour Control & 0.957 & All \\
Situational Factor & 0.937 & All \\
Subjective Norms & 0.960 & All \\
Personal Norms & 0.961 & All \\
Internal Attribution & 0.933 & All \\
Attitude & 0.914 & All \\
Perceived Consequences & 0.930 & All \\
Community Concern & 0.944 & All \\
\hline
\end{tabular}

The criteria-related validity is established when a criterion external to the measurement instrument is correlated with the factor structure (Nunnally, 1994). The criteria-related 
validity of the dimensions of PEB was measured by finding the correlation of each one of them with a PEB measure. All the correlations were significant at 0.05 significance level. The results of the correlation analysis are shown in Table 2.

Table 2. Pearson's correlation analysis of the constructs

\begin{tabular}{lcccccccccc}
\hline & B & BI & PBC & SF & SN & PN & IA & AT & CC & PC \\
\hline B & $\mathbf{1 . 0 0 0}$ & 0.374 & 0.497 & 0.148 & 0.215 & 0.222 & 0.113 & 0.217 & 0.076 & 0.151 \\
BI & 0.374 & $\mathbf{1 . 0 0 0}$ & 0.332 & 0.271 & 0.339 & 0.366 & 0.162 & 0.364 & 0.182 & 0.195 \\
PBC & 0.497 & 0.332 & $\mathbf{1 . 0 0 0}$ & 0.185 & 0.229 & 0.201 & 0.142 & 0.148 & 0.157 & 0.134 \\
SF & 0.148 & 0.271 & 0.185 & $\mathbf{1 . 0 0 0}$ & 0.143 & 0.197 & 0.163 & 0.197 & 0.131 & 0.114 \\
SN & 0.215 & 0.339 & 0.229 & 0.143 & $\mathbf{1 . 0 0 0}$ & 0.224 & 0.051 & 0.208 & 0.059 & 0.130 \\
PN & 0.222 & 0.366 & 0.201 & 0.197 & 0.224 & $\mathbf{1 . 0 0 0}$ & 0.126 & 0.213 & 0.096 & 0.085 \\
IA & 0.113 & 0.162 & 0.142 & 0.163 & 0.051 & 0.126 & $\mathbf{1 . 0 0 0}$ & 0.096 & 0.055 & 0.095 \\
AT & 0.217 & 0.364 & 0.148 & 0.197 & 0.208 & 0.213 & 0.096 & $\mathbf{1 . 0 0 0}$ & 0.105 & 0.186 \\
CC & 0.076 & 0.182 & 0.157 & 0.131 & 0.059 & 0.096 & 0.055 & 0.105 & $\mathbf{1 . 0 0 0}$ & 0.082 \\
PC & 0.151 & 0.195 & 0.134 & 0.114 & 0.130 & 0.085 & 0.095 & 0.186 & 0.082 & $\mathbf{1 . 0 0 0}$ \\
\hline
\end{tabular}

B-Behaviour, Bi- Behavioural intention, ATT-Attitude, PN- Personal norms, SN-Subjective norms, PBC- Perceived behavioural control, SF- Situational factors, CC- Community concern, IA- Internal Attribution, PC- Perceived consequences.

The two variables namely perceived consequences and the community concern were found to be more correlated with other determinants of PEB. Thus, the individuals who are more likely to engage in PEB are more likely to be concerned about environmental issues and the negative impact of their actions on the environment and their community. The attitude and personal norms are found to be more influential in motivating the behavioural intention of individuals to engage in PEB.

The results of the current study suggest that socio-psychological research can play a substantial role in the development of interventions to promote the attainment of a sustainable future. Interventions programmes and strategies can play an effective role in increasing the active participation in environmental activities at the individual level. However, the effectiveness of behavioural interventions generally increases when they are aimed at key antecedents of the relevant behaviour and at removing barriers for change. In reality, intervention programmes that work best should combine individual attitude (favour or disfavour), personal values and situational factors in the design of strategies for encouraging PEBs. Further, the intervention programmes should keep people up-to-date about environmental changes, resource usage etc. to determine whether or not intervention programmes delivers the intended output. 


\section{Conclusion}

The purpose of the current study was to examine the antecedents of PEB by using an integrated waste management behaviour model. The TPB and NAM provides a theoretical framework in which to integrate a wide variety of important factors from previous research on environmental behaviour. The present study was primarily a psychological investigation of the intrapsychic relationship between affective, cognitive and behavioural components of pro-environmental actions. Cognitive psychological modelling can provide the means to identify the driving forces behind PEB and in a given area determine the main likely success factors. Once these factors have been established, cost-effective campaigns can be designed to maximise the outcome. The TPB provided a cognitive framework to understand and explain behaviour, and its use in this study has provided valuable insights into the factors which underpin waste minimisation behaviour. This information can then be used to develop and implement waste minimisation schemes which are user-friendly.

Overall, the utility of the framework, based on social-psychological constructs, has considerable potential to advance the academic and practical understanding of environmental behaviour. There are clear advantages for policy makers in that the framework recognises the importance of the value-action gap, incorporates a great range of variables and offers the potential to be of significant practical use.

\section{References}

Ajzen, I. (1985). From intentions to actions: A theory of planned behaviour (pp. 11-39)." In Action Control: From Cognition to Behavior, J. Kuhl and J. Beckmann, Eds. New York: Springer Verlag Springer Berlin Heidelberg. https://link.springer.com/chapter/10.1007 1978-3-642-69746-3_2.

Ajzen, I. (1991). The theory of planned behaviour. Organizational Behaviour and Human Decision Processes, 50(2), 179-211.

Ajzen, I., \& M. Fishbein (1980), Understanding Attitudes and Predicting Social Behavior. Englewood Cliffs, NJ: Prentice-Hall, Inc.

Ajzen, I., \& Madden, T. J. (1986). Prediction of goal-directed behaviour: Attitudes, intentions, and perceived behavioural control. Journal of Experimental Social Psychology, 22(5), 453-474.

Balderjahn, I. (1988). Personality variables and environmental attitudes as predictors of ecologically responsible consumption patterns. Journal of Business Research, 17(1), 51-56.

Bamberg, S., \& Möser, G. (2007). Twenty years after Hines, Hungerford, and Tomera: A new meta-analysis of psycho-social determinants of pro-environmental behaviour. Journal of Environmental Psychology, 27(1), 14-25.

Bamberg, S., Hunecke, M., \& Blöbaum, A. (2007). Social context, personal norms and the use of public transportation: Two field studies. Journal of Environmental Psychology, 27(3), 190-203. 


\section{Macrothink}

Bandura, A. (1977). Self-efficacy: toward a unifying theory of behavioural change. Psychological Review, 84(2), 191-215.

Bandura, A. (1982). Self-efficacy mechanism in human agency. American Psychologist, 37(2), 122-147.

Barr, S. (2004). What we buy, what we throw away and how we use our voice. Sustainable household waste management in the UK. Sustainable Development, 12(1), 32-44.

Barr, S. (2007). Factors Influencing Environmental Attitudes and Behaviors A UK Case Study of Household Waste Management. Environment and Behavior, 39(4), 435-473.

Barr, S., Gilg, A. W., \& Ford, N. J. (2001a). A conceptual framework for understanding and analyzing attitudes towards household-waste management. Environment and Planning A, 33(11), 2025-2048.

Berger, I. E., \& Corbin, R. M. (1992). Perceived consumer effectiveness and faith in others as moderators of environmentally responsible behaviors. Journal of Public Policy \& Marketing, 11(2), 79-89.

Churchill Jr, G. A. (1979). A paradigm for developing better measures of marketing constructs. Journal of Marketing Research, 16(1), 64-73.

Cronbach, L. J. (1951). Coefficient alpha and the internal structure of tests. Psychometrika, 16(3), 297-334.

Davies, A. (2003). Waste wars - public attitudes and the politics of place in waste management strategies. Irish Geography, 36(1), 77-92.

Fishbein, M. A., \& I. Ajzen (1975), Belief Attitude, Intention and Behavior: An Introduction to Theory and Research. Reading, MA: Addison-Wesley. Accessed from http://people.umass.edu/aizen/f\&a1975.html (March 15, 2017).

Harland, P., Staats, H., \& Wilke, H. A. (1999). Explaining proenvironmental intention and behavior by personal norms and the theory of planned behavior1. Journal of Applied Social Psychology, 29(12), 2505-2528.

Hines, J. M., Hungerford, H. R., \& Tomera, A. N. (1987). Analysis and synthesis of research on responsible environmental behavior: A meta-analysis. The Journal of Environmental Education, 18(2), 1-8.

Jackson, A. L., Olsen, J. E., Granzin, K. L., \& Burns, A. C. (1993). An investigation of determinants of recycling consumer behavior. Advances in Consumer Research, 20(1), 481-487.

McCarty, J. A., \& Shrum, L. J. (1993). A structural equation analysis of the relationships of personal values, attitudes and beliefs about recycling, and the recycling of solid waste products. Advances in Consumer Research, 20(1), 641-646. 


\section{Macrothink}

Issues in Social Science ISSN 2329-521X 2017, Vol. 5, No. 1

McCarty, J. A., \& Shrum, L. J. (1994). The recycling of solid wastes: Personal values, value orientations, and attitudes about recycling as antecedents of recycling behavior. Journal of Business Research, 30(1), 53-62.

Nunnally, J. C. (1978). Psychometric Theory. McGraw-Hill, New York, NY.

Nunnally, J. C., \& Bernstein, I. (1994). Psychometric theory. McGraw-Hill, New York, NY.

Pieters, R. G. (1991). Changing garbage disposal patterns of consumers: Motivation, ability, and performance. Journal of Public Policy \& Marketing, 10(2), 59-76.

Schwartz, S. H. (1977). Normative influences on altruism. Advances in Experimental Social Psychology, 10(1), 221-279.

Shekdar, A. V. (2009). Sustainable solid waste management: an integrated approach for Asian countries. Waste Management, 29(4), 1438-1448.

Triand is, H. C. (1979). Values, attitudes, and interpersonal behavior. In Nebraska symposium on motivation: Beliefs, Attitudes, and Values, 27(1), 195-259. University of Nebraska Press, Lincoln. [Online] Available: http://psycnet.apa.org/psycinfo/1982-21073-001 (March 19, 2017). 